\title{
Una vez más, de la vieja a la nueva epidemiología
}

\section{Once again, moving from the old to the new epidemiology}

\section{Rina M. Ramis Andalia}

Doctora en Medicina. Máster en Salud Pública. Profesor Auxiliar. Escuela Nacional de Salud Pública. La Habana, Cuba.

\section{RESUMEN}

Las nuevas generaciones de epidemiólogos han demorado mucho en comprender cabalmente las palabras de Nájera: "y aún estamos atenidos al enfoque newtoniano. Esa es la razón por la cual todavía pensemos las causas de las enfermedades en términos de uno, dos o cuando muchos unos pocos factores". Es necesario esforzarse en pensar de manera diferente. En este artículo se describen los modelos lineales de causalidad aún vigentes en la mayoría de los estudios epidemiológicos y se propone aceptar el nuevo desafío que representa reconocer una causalidad no lineal. Es interesante y necesario preguntarse si se adaptarán los epidemiólogos a expresarse en un lenguaje predominantemente cualitativo, si lograrán expresar los problemas de salud-enfermedad poblacional sin el predominio de las estadísticas, o si la tendencia general será a desarrollar una nueva forma de epidemiología cuantitativa desde las teorías y no desde las nuevas teorías de la complejidad, donde impera el carácter cualitativo. Actuar según el pensamiento de la complejidad constituye un verdadero desafío para el paradigma matemáticoestadístico positivista, que dominó el campo de la Epidemiología Clásica.

Palabras clave: Epidemiología Clásica, nueva epidemiología, teoría de la complejidad.

\section{ABSTRACT}

The new generations of epidemiologists have taken too much time in fully understanding Najera's words: "we are still tied to the Newton's approach. This is the reason why we are still thinking of the causes of diseases in terms of one, two or a few factors all the most". It is necessary to make efforts to change our minds. 
This article described the linear causality models that are yet valid in most of the epidemiological studies, and made suggestions to accept the new challenge of nonlinear causality. It is interesting and necessary to wonder if the epidemiologists will adapt to express themselves in a predominantly qualitative language, if they will manage to state the population 's health-disease problems without statistics or if the general tendency will be developing a new form of quantitative epidemiology based on theories rather than on the new complexity theories where the qualitative nature predominates. Acting in line with the complexity thinking is a real challenge for the positivist mathematician-statistician paradigm that has so far prevailed in the field of Classical Epidemiology.

Key words: Classical Epidemiology, new epidemiology, the theory of complexity.

\section{INTRODUCCIÓN}

Preparando mis clases sobre causalidad para los alumnos de la residencia de higiene y epidemiología, revisaba nuevamente la parte III de "El Desafío de la Epidemiología", relacionada con el capítulo de Discusión que sostienen Enrique Nájera, Carol Buck y Milton Terris, cuando descubrí algo que estuvo oculto a mi visión, y de lo que solo tuve durante muchos años, una comprensión parcial de su total significado. A continuación cito:

Es mas fácil hablar acerca de una red que trabajar con ella, recuerdo haber leído un trabajo muy bueno preparado por Capra, en el que seguía la gran evolución de la física desde Newton hasta la teoría de la relatividad y la comparaba con la relativa falta de un desarrollo similar de las ciencias aplicadas... En realidad no podemos comprender la red de causalidad porque eso sería comparable para comprender el concepto de relatividad. En medicina por ejemplo, aún estamos atenidos al enfoque newtoniano. Esa es la razón por la cual todavía pensemos las causas de las enfermedades en términos de uno, dos o cuando muchos unos pocos factores. Deberíamos por lo menos saber un poco más de Física... Tenemos que esforzarnos a pensar de manera diferente... Tal vez sea más fácil para las nuevas generaciones hacerlo así...

ENRIQUE NÁJERA

El Desafío de la Epidemiología, problemas y lecturas seleccionadas. Washington: OPS; 1988.

Quizás las nuevas generaciones de epidemiólogos han demorado mucho en comprender cabalmente el significado de las palabras de Nájera, pero cada vez es más evidente la necesidad de trabajar con una visión transdisciplinar en estos u otros desafíos.

\section{EL PROBLEMA}

En la actualidad, la epidemiología debe enfrentar varios problemas epistemológicos. De ellos, quizá el más importante es el problema de la causalidad, aspecto sobre el que todavía no existe consenso entre los expertos. 
La enconada lucha de los inicios del siglo XIX, entre contagionistas y seguidores de la teoría miasmática, aún persiste en el siglo Xx y XXI, aunque con matices diferentes. El abanico de posturas se extiende desde los que proponen generalizar el uso de los postulados de causalidad, sean estos los de Henle-Koch, los de Bradford Hill o los de Evans, hasta los que consideran que la epidemiología debe abandonar el concepto de "causa" y limitarse a dar explicaciones no deterministas de los eventos que investiga. El asunto aún no ha sido resuelto, por lo que se mantiene en el centro de la polémica. ${ }^{1-5}$

Las críticas al concepto de causa, formuladas por primera vez por David Hume en 1740 , probablemente implicarían replantear conceptos tan arraigados en la investigación epidemiológica como los de "causa necesaria", "componente de causas suficientes" o "riesgo atribuible", por ejemplo. ${ }^{1,5}$

Dado que estas críticas son cada vez más aceptadas por las ciencias naturales, es indudable que este tema seguirá siendo uno de los predilectos de la literatura epidemiológica del siglo XXI. ${ }^{1}$

\section{TEORÍAS Y MODELOS CAUSALES EN EPIDEMIOLOGÍA}

El concepto de causalidad en epidemiología, ha estado históricamente relacionado con el pensamiento filosófico predominante en cada época, los avances alcanzados por las ciencias en general y las ciencias de la salud en particular y con los problemas que en cada época han afectado y predominado en la salud de las poblaciones humanas.

Las propuestas para el estudio de la causalidad durante el pasado siglo $\mathrm{xx}$, se basaron fundamentalmente en los modelos epidemiológicos de causas únicas/efectos únicos (monocausal) o causas múltiples/efectos múltiples (multicausal), de modo que en la evolución histórica de la causalidad en Epidemiología se reconocen las siguientes teorías y modelos causales. ${ }^{6-8}$

\section{Causalidad debida a miasmas}

Antes del surgimiento de la Epidemiología como ciencia, existía la creencia de que las enfermedades eran producidas por emanaciones, aire "pútrido" u otros "humores" (miasmas). Esta forma de pensamiento predominó hasta el descubrimiento de las bacterias por Louis Pasteur en 1860. En su etapa final, la creencia en la teoría de los miasmas, rivalizó con la naciente teoría del contagio.

\section{Causas únicas-efectos únicos}

Se extiende desde el descubrimiento de las bacterias por Louis Pasteur, hasta la primera mitad del siglo xx. En los inicios del siglo xx se creía que bastaba solo la presencia del agente infeccioso para que la enfermedad que este ocasionaba, se manifestara. Pronto los investigadores se percataron, que para que esto ocurriera era necesario la presencia de otros elementos. Los conceptos de causa necesaria y causa suficiente introducidos en este modelo fueron rescatados del pensamiento filosófico galileano. El modelo explicativo de causas únicas y de corte monocausal, dio origen posteriormente al Ilamado modelo ecológico, según el cual, los 
problemas de salud se explicaban por la relación agente-huésped en un determinado ambiente.

Durante esta etapa se trabaja intensamente en el estudio y control de las enfermedades infecciosas que azotaron a la humanidad durante siglos anteriores, se descubrieron los antibióticos, se realizaron grandes obras sanitarias, se descubrieron múltiples vacunas y se realizaron grandes campañas mundiales a favor del control de las enfermedades infecciosas.

Se inicia el uso de la investigación exploratoria descriptiva y el uso de la estadística descriptiva y sanitaria en los estudios epidemiológicos.

\section{Causa múltiples-efectos únicos}

Al disminuir las enfermedades infecciosas y aumentar las crónicas, se produce una transición de los perfiles epidemiológicos en algunos países, algunos autores visualizan una etapa de tránsito que se reconoce como el modelo "de causas múltiples-efectos únicos."

\section{Causas múltiples-efectos múltiples. Segunda mitad del siglo xx}

Se inicia en el momento que comienzan a declinar en los países desarrollados las enfermedades infecciosas y se incrementan las enfermedades no transmisibles. Tiene una etapa de tránsito con el modelo anterior, cuando se identifican varios agentes biológicos capaces de producir una misma enfermedad. Después de los primeros estudios realizados por Richard Doll y Bradford Hill, se reconoce la relación de diversos factores con la ocurrencia de enfermedades no transmisibles.

En 1960 Mac Mahon propone el concepto de factores de riesgo para identificar posibles elementos causales, participantes en la ocurrencia de estas enfermedades, denominándose riesgo al peligro de adquirir la enfermedad. Los estudios de factores de riesgo permitieron aplicar la teoría de probabilidad en la epidemiología, comenzar el uso de la estadística inferencial, con ello la investigación analítica y experimental se expande y la epidemiología centra su interés en el estudio de factores de riesgo, alejándose del escenario de la población en general.

Posteriormente, Mervyn Susser y Ezra Susser, con una visión sistémica aunque jerárquica, propusieron un nuevo modelo que ellos denominan "ecoepidemiológico" o de las cajas chinas, ${ }^{8}$ y que consideramos supera las limitaciones conceptuales del modelo de factores de riesgo de Mac Mahon, sin embargo, Jaime Breilh considera que:

Esta propuesta establece una dicotomía mecánica entre elementos sociales e individuales relegados a sistemas distintos, niega la relación dialéctica entre fenómenos sociales e individuales, desdeña al individuo como personificación de hechos sociales fundamentales, su carácter representativo de intereses y relaciones de clases, y lo convierte en una unidad funcional influida desde fuera por la clase social que actúa como algo exterior. ${ }^{7}$

De este modo, el modelo de causalidad múltiple de Mac Mahon no sobrepasa las limitaciones del modelo causal clásico o lineal, basado en una causalidad analítica, fragmentada en partes aisladas, que no articula armónicamente lo individual con lo poblacional. Por otra parte, el modelo "ecoepidemiológico" de Susser, enfrenta 
escollos conceptuales, dado que no logra resolver el problema de la dicotomía entre lo individual y lo social ni la jerarquía entre niveles.

Geoffrey Rose, había expresado hacia la mitad de la década del 80, que los factores que tienen que ver con la ocurrencia de casos de enfermedad en una población determinada, son diferentes a los factores que explicarían las diferencias en la aparición de las enfermedades entre distintas poblaciones. ${ }^{8}$ De modo que el concepto de causalidad centrado en enfermos y enfermedades, se extiende a las causas del proceso salud-enfermedad.

El concepto de causalidad a nivel individual se torna insuficiente para comprender la participación de una causalidad que abarca no solo al individuo, ni a los grupos de individuos, sino que desea enfrentar problemas de salud poblacionales. ${ }^{1}$

No existe un modelo causal lineal que vincule las relaciones causales que se producen entre lo micro (a nivel individual) y lo macro (a nivel social), la causalidad así comprendida parece ser imposible de ser aprehendida con los conocimientos, instrumentos y herramientas brindados por las estadísticas y el cálculo de probabilidades. Las ciencias sociales comienzan a llenar el espacio de comprensión desde lo social.

La epidemiología clásica, centrada en la comprensión de la población desde lo individual y basada en los principios de la causalidad lineal, logró estudiar los problemas de salud, considerando al individuo contenido como parte de un todo poblacional. Su enfoque, acorde con el desarrollo de las ciencias analíticas de su época, desmembró a la población en sus partes (individuos), adoptando un concepto estadístico poblacional como la suma de todas sus partes (individuos), y desde esta perspectiva la teoría causal de los factores de riesgo incluyó a lo social como un factor de riesgo más.

\section{¿CÓMO ESTUDIAR, DESDE LA EPIDEMIOLOGÍA, ESTOS NUEVOS TIPOS DE RELACIONES CAUSALES?}

El principio clásico de la causalidad prevaleciente en la modernidad no es útil para explicar las interacciones causales circulares que se establecen en los sistemas complejos abiertos, que son las formas más frecuentes de movimiento que predominan en la naturaleza y en la sociedad. Nuevas teorías como la del caos, las de las catástrofes, las de los fractales y las de redes, pueden contribuir a brindar los fundamentos teóricos y prácticos para iniciar un camino explicativo hacia los fenómenos que interactúan de forma diferente con el entorno y por tanto, pueden ser útiles para emprender el estudio de estas nuevas relaciones causales. No se debe olvidar que hasta el momento los mayores desarrollos en estas teorías son de carácter cualitativo más que cuantitativo, lo que constituye un verdadero desafío para el paradigma matemático-estadístico positivista que dominó el campo de la epidemiología clásica.

Cabría preguntarse, ¿se adaptarán los epidemiólogos a expresarse en un lenguaje predominantemente cualitativo?, ¿lograrán expresar los problemas de saludenfermedad poblacional sin el predominio de las estadísticas; o es que la tendencia general será a desarrollar una nueva forma de epidemiología cuantitativa desde las teorías y no desde el pensamiento de la complejidad? Los nuevos tiempos imponen nuevos desafíos, no olvidemos que se trata de un área del saber que históricamente ha tenido un carácter eminentemente práctico. 


\section{REFERENCIAS BIBLIOGRÁFICAS}

1. OPS. El desafío de la Epidemiología. Problemas y lecturas seleccionadas.

Publicación Científica 505. Washington, D.C.: OPS;1989.

2. López Moreno S. Acerca del Estatuto Científico de la Epidemiología. Salud Pública Méx. 1998;40(5):389-91.

3. Ramis Andalia RM. La causalidad compleja: ¿un nuevo paradigma causal en Epidemiología? Rev Cubana Salud Pública [Internet]. 2004 Sep [citado 27 Jul 2011];30(3). Disponible en:

http://scielo.sld.cu/scielo.php?script=sci arttext\&pid=S0864-

$\underline{34662004000300010 \& \operatorname{lng}=\mathrm{es}}$

4. Introducción a la relación causa efecto [Internet]. 2008 [citada 23 Nov 2008]. Disponible en:

http://ccp.ucr.ac.cr/cursos/epidistancia/contenido/4 epidemiologia.htm

5. Marecos E. La causalidad, la casualidad, la medicina. Revista Posgrado Cátedra VIa Medicina. 2001:2(101)14-20.

6. Martínez Álvarez H, Pérez Campos E. Causalidad en medicina. Gac Méd Méx. $2004 ; 140(4)$.

7. Caraballoso Hernández M. Causalidad en Epidemiología. Diplomado de Higiene y Epidemiología. La Habana: Escuela Nacional de Salud Pública; 2008.

8. Susser M, Susser E. Choosing a future of Epidemiology. Part II. From black box to Chinese boxes and ecoepidemiology. Am J Public Health. 1996;86(5):674-7.

Recibido: 2 de junio de 2011.

Aprobado: 22 de junio de 2011.

Rina M. Ramis Andalia. Escuela Nacional de Salud Pública. Calle 100 No. 10132 e/ Perla y E. Altahabana, Boyeros. La Habana, Cuba.

Correo eletrónico: rina.ramis@infomed.sld.cu 